\title{
Research of the flow-over of the mechanical core of four pipes by a wind current, using Control Volume Method
}

\author{
Dmitry Chernyshev ${ }^{1}$, and Vadim Alpatov ${ }^{1, *}$ \\ ${ }^{1}$ Samara State Technical University, Institute of Architecture and Civil Engineering, \\ 194, Molodogvardeyskaya St., 443001, Samara, Russia
}

\begin{abstract}
One of the most important stages of designing the framework of high-rise stacks is the calculation of loads on the stack and on the mechanical core of the gas outlet pipes located inside the stack. In current normative documents there is no data on the aerodynamics of the mechanical core. At the same time the aerodynamic coefficients of pipes in the core differ from the aerodynamic coefficients of single cylinders. When dealing with gas dynamics problems, program complexes in which control volume method is applied are getting widespread use. When problems are solved in such complexes, the speed of wind current and the size of the structure are selected, and the required Reynolds numbers similarity is achieved. This paper presents the results of the research which deals with the flow-over of the mechanical core of four pipes in the gas-dynamic complex STAR-CD, the work of which is based on control volume method. In the research two options of the mechanical core model are considered, depending on the cylinders' relative position. The first option is the ratio of the distance between the cylinders' centers $1.5 \mathrm{~d}$, the second option is the ratio 2 . For each design option the flow-over by the wind current at three angles of attack $0^{0}, 30^{\circ}$ and $45^{\circ}$ is simulated.
\end{abstract}

\section{Introduction}

One of the most important stages of designing the framework of high-rise stacks is the calculation of loads on the stack and on the mechanical core of the gas outlet pipes located inside the stack. In current normative documents there is no data on the aerodynamics of the mechanical core. At the same time the aerodynamic coefficients of pipes in the core differ from the aerodynamic coefficients of single cylinders [1-3].

\section{Materials and methods}

To determine the real values of the aerodynamic parameters of the pipes in the mechanical core, it is necessary to carry out field observations of their flow-over in a wind tunnel. During flow-over the model, it is necessary to observe the Reynolds numbers similarity of

*Corresponding author: avu75@mail.ru 
the model and the real structure. Models of high-rise structures turn out to be quite sizeable. That's why in some cases such similarity can not be achieved. It requires the use of large wind tunnels, which are not always accessible.

Recently, when dealing with gas dynamics problems, program complexes in which control volume method is applied have been getting widespread use. When problems are solved in such complexes, the speed of wind current and the size of the structure are selected, and the required Reynolds numbers similarity is achieved. This paper presents the results of the research which deals with the flow-over of the mechanical core of four pipes in the gas-dynamic complex STAR-CD, the work of which is based on control volume method.

The main idea of the method is that the domain of computation is divided into a number of control volumes, so that one nodal point is contained in one control volume. Differential equations are integrated over each volume. Using patch profiles, a discrete analogue of the differential equation is found, which includes the values of the variable of interest for several nodal points.

One of the important features of control volume method is that it implies the exact integral preservation of such values as mass, momentum and energy for any group of control volumes and, therefore, for the entire domain of computation. This is true for any number of nodal points, not only for the borderline case of their very large number. So, even the solution based on a very rough mesh satisfies accurate integral balances.

\section{Results}

Purposes of the research:

1) To determine the values of the pressure caused by the wind current at certain points on the surface of the pipes;

2) To obtain the integral parameters of the current (longitudinal and transverse aerodynamic coefficients) for each pipe and for the whole mechanical core;

3) To research the patterns of direction and the values of speeds, as well as the nature of the current in the areas near the cylinders.

Research objective. Stacks with a mechanical core of flue gas pipes are designed $100 \mathrm{~m}$ - $250 \mathrm{~m}$ high [4]. The diameter of the gas-outlet pipes in the mechanical core varies from 1 to $3.5 \mathrm{~m}$. The distance between the centers of the flue gas pipes with respect to the diameter of the pipe is usually in the ratio of $(L / D)=1,5-2$, where $\mathrm{L}$ is the distance between the pipes, and $\mathrm{D}$ is the diameter of the flue gas pipe.

The characteristic value of wind pressure $W_{0}(\mathrm{~Pa})$ is determined from the formula:

$$
W_{0}=0,5 \cdot \rho \cdot V^{2},
$$

where $V$ is wind current speed, and $\rho=1,22 \mathrm{~kg} / \mathrm{m}^{3}$ is atmospheric density. In current normative documents the speed is the speed of wind at the height of $10 \mathrm{~m}$ above ground level for the type of locality A by ten-minute averaging and the frequency of 5 years.

The characteristic value of the central component of wind load $W_{n}$ at the height $z$ above ground level, according to [5], is:

$$
W_{u}=W_{0} \cdot k_{z} \cdot c,
$$

where $k_{z}$ is the factor taking into account the height variation of wind pressure, and $c$ is the aerodynamic coefficient. 
The movement of air mass in the boundary layer of up to $200 \mathrm{~m}$ is turbulent. The speed of air movement consists of the average component $\bar{V}$ and the pulsation component $V^{\prime}$ : $V=\bar{V}+V^{\prime}$. The pulsation component is positive at some time points, at other time points it is negative, and its average time value is zero. As shown in paper [6], turbulent flow is considered to be a stationary random process with the average value equal to zero.

Solving the problems of turbulent fluid flows allows obtaining satisfactory data and thus simulating the behavior of real turbulent flows. The models of turbulence are described by a system of additional equations (as well as associated algebraic relations and a set of constants), that are solved together with the Navier-Stokes equation.

There is a wide variety of models of turbulence. In this paper calculations using STAR$\mathrm{CD}$ program are made basing on the so-called two-parameter "high-Reynolds $k-\varepsilon$ model". Unlike other two-parameter models, $k-\varepsilon$ model is the most universal one from the point of view of forecasting turbulent effects [7]. Here $k$ is the specific kinetic energy of turbulent pulsations, $k=\left(3 \cdot \gamma^{2}\right) / 2$, where $\gamma$ is turbulence intensity, $\varepsilon$ is dissipation rate of turbulent energy, connected with the scale of turbulence $L$ (the characteristic size of turbulent vortices in the direction of the midstream).

Modeling the flow-over of the mechanical core of pipes using STAR-CD program.

The requirements to make calculations for different angles of attack by the wind current lead to the necessity to rotate the researched core of cylinders. For this purpose, an intermediate cylindrical element [5], [8] is built in the mesh, which allows obtaining a new mesh with the given angle of attack of ram air current, by means of circular shift of the calculation model nodes in the required direction. The program has modeled the cross sections of the cylinders of the core, and the plane problem has been dealt with.

The cell dimensions of the mesh of voxels are described in detail in paper [8].

The initial conditions of the problem are: a resting medium.

Boundary conditions of the problem:

1. The input for the domain of computation is the speed of the current $V_{n}=25 \mathrm{~m} / \mathrm{s}$ and the turbulence intensity $\gamma=1 \%$.

2. The output is the condition for pressure constancy $p=p_{\infty}$.

3. On the remote external lateral boundaries it is the condition of an aerodynamically smooth wall (the speed vector is parallel to the lateral boundary of the domain of computation). The dimensions of the workspace are defined in paper [1].

4. On the internal boundary (on the perimeter of the cylinders) the adhesion condition (zero speed) is set.

5. The time step is $0.001(\mathrm{~s})$.

\section{Discussion}

The results of the research of the flow-over of the mechanical core of four pipes. In the research two options of the mechanical core model are considered, depending on the cylinders' relative position. The first option is the ratio of the distance between the cylinders' centers $L / D=1,5$, the second option is $L / D=2$. For each design option flowover by the wind current at three angles of attack $0^{\circ}, 30^{\circ}$ and $45^{\circ}$ is simulated.

The results of the longitudinal and transverse aerodynamic coefficients of separate cylinders and of the whole mechanical core are presented in Table 1. The patterns of flowover of the mechanical core by the wind current at different angles of attack for the option $L / D=2$ are shown in Figures 1-3. 
Table 1. The results of the research of the flow-over of the mechanical core of four pipes.

\begin{tabular}{|c|c|c|c|}
\hline \multirow[t]{2}{*}{ № } & \multirow{2}{*}{$\begin{array}{l}\text { Distance between the pipes' diameters } \\
\text { and the angle of attack by the wind } \\
\text { current }\end{array}$} & \multicolumn{2}{|c|}{$\begin{array}{l}\text { Longitudinal } C_{X} \text { and transverse } C_{Y} \\
\text { aerodynamic coefficients }\end{array}$} \\
\hline & & $\mathrm{C}_{\mathrm{X}}$ & $\mathrm{C}_{\mathrm{Y}}$ \\
\hline 1 & $\sum_{L / D=1,5 ; \text { angle of attack } 0^{0}}^{2}$ & $\begin{array}{c}\mathrm{C}_{\mathrm{X} 1}=0,29 \\
\mathrm{C}_{\mathrm{X} 2}=0,29 \\
\mathrm{C}_{\mathrm{X} 3}=0,32 \\
\mathrm{C}_{\mathrm{X} 4}=0,32 \\
\Sigma=1,22\end{array}$ & $\begin{array}{c}\mathrm{C}_{\mathrm{Y}_{1}}=-0,12 \\
\mathrm{C}_{\mathrm{Y} 2}=0,12 \\
\mathrm{C}_{\mathrm{Y} 3}=-0,28 \\
\mathrm{C}_{\mathrm{Y} 4}=0,29 \\
\Sigma=0,01\end{array}$ \\
\hline 2 & $L / D=1,5 ;$ angle of attack $30^{\circ}$ & $\begin{aligned} \mathrm{C}_{\mathrm{X} 1} & =0,41 \\
\mathrm{C}_{\mathrm{X} 2} & =0,62 \\
\mathrm{C}_{\mathrm{X} 3} & =0,47 \\
\mathrm{C}_{\mathrm{X} 4} & =-0,07 \\
\Sigma & =1,43\end{aligned}$ & $\begin{array}{l}\mathrm{C}_{\mathrm{Y} 1}=0,04 \\
\mathrm{C}_{\mathrm{Y} 2}=0,42 \\
\mathrm{C}_{\mathrm{Y} 3}=0,28 \\
\mathrm{C}_{\mathrm{Y} 4}=-0,2 \\
\Sigma=-0,54\end{array}$ \\
\hline 3 & $L / D=1,5 ;$ angle of attack $45^{\circ}$ & $\begin{aligned} \mathrm{C}_{\mathrm{X} 1} & =0,43 \\
\mathrm{C}_{\mathrm{X} 2} & =0,75 \\
\mathrm{C}_{\mathrm{X} 3} & =0,43 \\
\mathrm{C}_{\mathrm{X} 4} & =-0,17 \\
\Sigma & =1,44\end{aligned}$ & $\begin{array}{c}\mathrm{C}_{\mathrm{Y} 1}=-0,07 \\
\mathrm{C}_{\mathrm{Y} 2}=0 \\
\mathrm{C}_{\mathrm{Y} 3}=0,07 \\
\mathrm{C}_{\mathrm{Y} 4}=0 \\
\Sigma=0\end{array}$ \\
\hline 4 & $\sum_{L / D=2 ; \text { angle of attack } 0^{0}}^{2}$ & $\begin{array}{c}\mathrm{C}_{\mathrm{X} 1}=0,26 \\
\mathrm{C}_{\mathrm{X} 2}=0,26 \\
\mathrm{C}_{\mathrm{X} 3}=0,37 \\
\mathrm{C}_{\mathrm{X} 4}=0,37 \\
\Sigma=1,26\end{array}$ & $\begin{array}{c}\mathrm{C}_{\mathrm{Y}_{1}}=-0,05 \\
\mathrm{C}_{\mathrm{Y} 2}=0,05 \\
\mathrm{C}_{\mathrm{Y} 3}=-0,21 \\
\mathrm{C}_{\mathrm{Y} 4}=0,21 \\
\Sigma=0\end{array}$ \\
\hline 5 & $L / D=2 ;$ angle of attack $30^{\circ}$ & $\begin{array}{c}\mathrm{C}_{\mathrm{X} 1}=0,33 \\
\mathrm{C}_{\mathrm{X} 2}=0,46 \\
\mathrm{C}_{\mathrm{X} 3}=0,44 \\
\mathrm{C}_{\mathrm{X} 4}=0,16 \\
\Sigma=1,39\end{array}$ & $\begin{aligned} \mathrm{C}_{\mathrm{Y} 1} & =0,09 \\
\mathrm{C}_{\mathrm{Y} 2} & =0,18 \\
\mathrm{C}_{\mathrm{Y} 3} & =0,04 \\
\mathrm{C}_{\mathrm{Y} 4} & =-0,04 \\
\Sigma & =0,27\end{aligned}$ \\
\hline
\end{tabular}




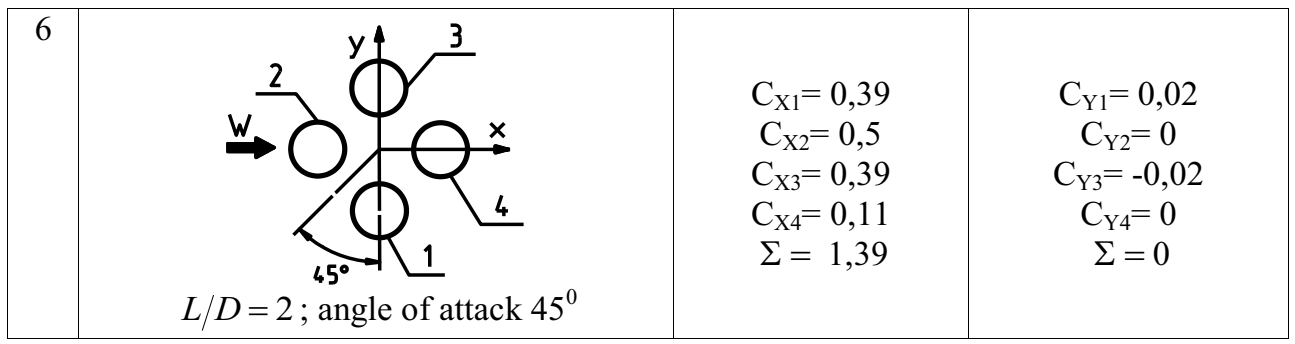

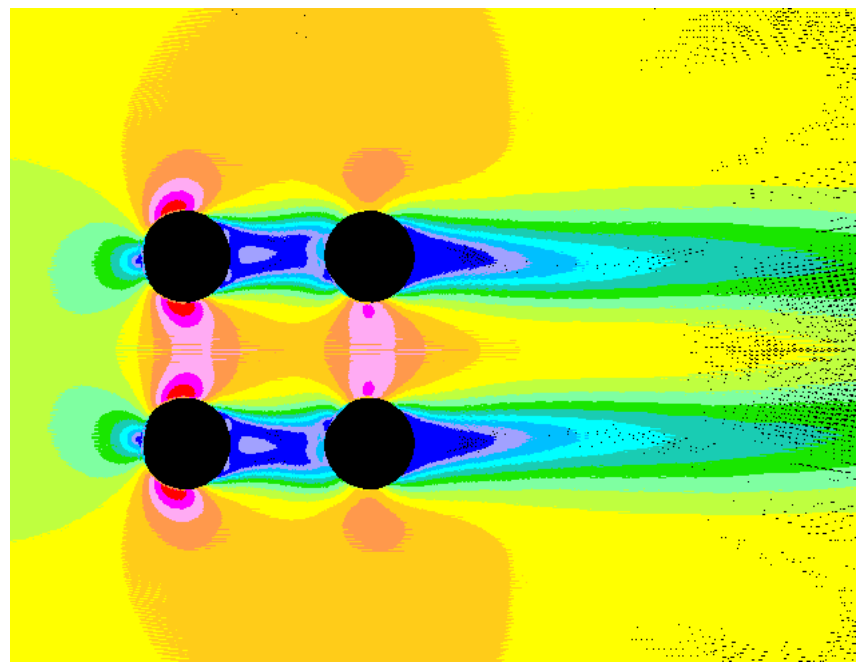

Fig. 1. Wind current speed field, by $L / D=2$, angle of attack $0^{0}$.

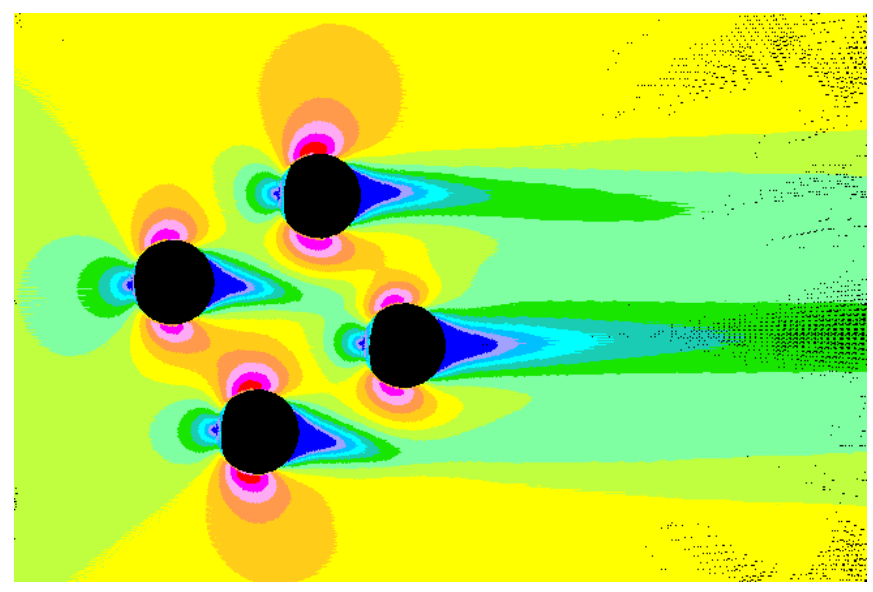

Fig. 2. Wind current speed field, by $L / D=2$, angle of attack $30^{\circ}$. 


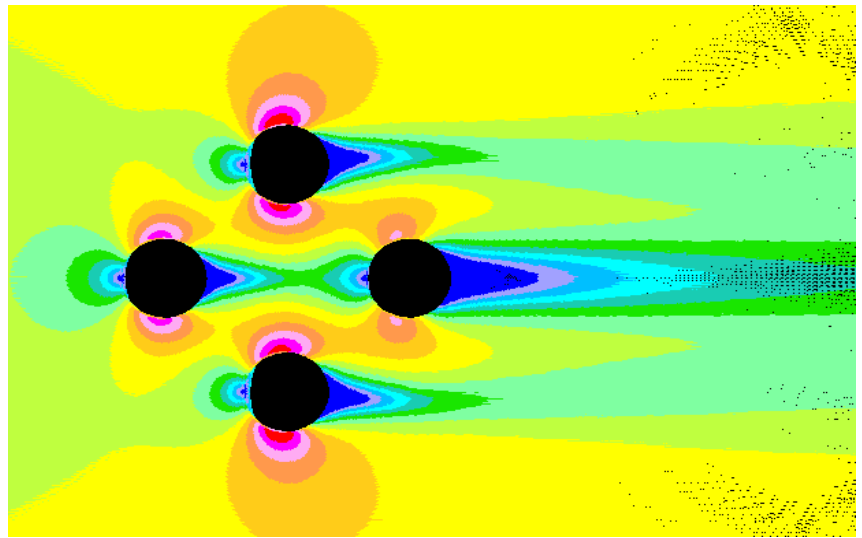

Fig. 3. Wind current speed field, by $L / D=2$, angle of attack $45^{\circ}$.

\section{Conclusions}

Conclusions and results of the research:

1. On the basis of control volume method, the problem of the flow-over of the mechanical core of four flue gas pipes' cylinders by a wind current is simulated.

2. The longitudinal and transverse aerodynamic coefficients of separate pipes and of the whole mechanical core are determined. The aerodynamic coefficients are determined for different angles of attack by the wind current and for different distances between the pipe's centers.

3. Wind current speed fields of the mechanical core of four pipes are obtained for different angles of attack and for different distances between the pipe's centers.

4. The results obtained may be useful for calculating the wind load when designing stack structures with the mechanical core of four similar gas-outlet pipes.

\section{References}

1. A.V. Atamanchuk, Extended abstract of candidate of technical sciences dissertation (Samara, 2005)

2. I.S. Kholopov, Analysis of structures and buildings under dynamic loading (Samara, 2008)

3. I.S. Kholopov, Analysis of structures and buildings under dynamic loading (Association of higher educational institutions of civil engineering, Moscow, 2008)

4. M.B. Solodar, M. V. Kuznetsova, Yu.S. Plishkin, Metal structures of stacks (Stroyizdat, Leningrad, 1975)

5. D.D. Chernyshev, K.V. Yashukov, A.V. Atamanchuk, News of higher educational institutions. Civil engineering 9, 107-112 (2010)

6. E. Simiu, R. Skanlan, Impact of wind on buildings and structures (Stroyizdat, Moscow, 1984)

7. L.G. Loitsansky, Mechanics of liquid and gas (Drofa, Moscow, 2003)

8. D.D. Chernyshev, I.S. Kholopov, A.V. Atamanchuk, Industrial and Civil Engineering 11, 40-42 (2009) 